\title{
Moa Martinson
}

\section{November I890 in Vårdnäs (Schweden) \\ † 5.August 1954 in Sorunda (Schweden)}

(auch: Helga Maria Johansson) - Ausbildung zur Kellnerin; hatte fünf Söhne mit dem Gelegenheitsarbeiter Karl Johansson; 1922 Debüt als Autorin in der linksradikalen Presse; 1929 Heirat mit dem Schriftstellerkollegen Harry Martinson; Autodikaktin und Proletarierautorin, die autobiographische Erlebnisse aus dem Arbeitermilieu beschrieb; Konzentration auf die Situation der Arbeiterfrauen.

\section{Mutter heiratet / Mor gifter sig}

Der sozialkritische Roman, erschienen 1936, beginnt mit dem Satz: "Ich erinnere mich so gut an den Tag, an dem Mutter heiratete.« Als Mitarbeiterin in der schwedischen Arbeiterpresse hatte die sogenannte Proletarierschriftstellerin gelernt, die Literatur in erster Linie als Waffe im sozialen Kampf zu betrachten. Der Inhalt des in Ichform verfassten Romans ist weitgehend autobiographisch. Realistisch und unsentimental schildert die Autorin Erinnerungen an eine elende Kindheit im Arbeitermilieu um die Wende zum 20. Jh.

Das uneheliche Kind Mia erlebt die Hochzeit seiner Mutter mit dem zukünftigen Stiefvater Alfred, der sich als Alkoholiker und unglückseliger `Don Juan entpuppt. Er verlässt seine Frau jedes Mal, wenn sie schwanger ist, kehrt dann aber, von Reue gepackt, regelmäßig nach der Geburt des Kindes wieder zurück. Während Alfred fast ausschließlich von außen gesehen wird, wird Hedvig, die Mutter, eine tapfere, selbst im größten Elend noch liebevolle Frau, differenzierter dargestellt. Einzelne Details aus dem Lebensbereich der Mutterso malt sie blaue Blumen an die kalkigen Wände der Küche, um sie freundlicher zu gestalten - werden mit feinsinniger Wärme erzählt, während der unprätentiöse knappe Stil ansonsten wenig Emotionen zulässt. Charakteristisch sind vor allem die grotesken Gegenüberstellungen des Verhaltens der Erwachsenen mit den Reflexionen des Kindes sowie humorvoll-realistische Schilderungen drastischer Einzelheiten aus der täglichen Armseligkeit des Lebens, die den Einfluss Gor'kijs verraten. BÄRBEL MEYER-DETTUM 